Int. J. Electrochem. Sci., 11 (2016) $7380-7394$

\title{
Synergistic Coupling Between Electrochemical and Ultrasound Treatments for Organic Pollutant Degradation as a Function of the Electrode Material ( $\mathrm{IrO}_{2}$ and BDD) and the Ultrasonic frequency $(20$ and $800 \mathrm{kHz})$
}

\author{
Fernando L. Guzman-Duque ${ }^{1}$, Christian Pétrier, ${ }^{2,3,}$, Cesar Pulgarin $^{4}$, Gustavo Peñuela ${ }^{1}$, \\ Erika Herrera-Calderón ${ }^{5}$, Ricardo A. Torres-Palma ${ }^{6, *}$ \\ ${ }^{1}$ Grupo de diagnóstico y control de la contaminación, Facultad de Ingeniería, Universidad de \\ Antioquía, A.A. 1226, Medellín, Colombia. \\ ${ }^{2}$ Laboratoire Rhéologie et Procédés, 1301 Rue de la piscine, BP 53 Domaine Universitaire, 38041 \\ GRENOBLE cédex 09, France \\ ${ }^{3}$ King Abdulaziz University, Jeddah, Saudi Arabia \\ ${ }^{4}$ Institute of Chemical Sciences and Engineering, GGEC, Swiss Federal Institute of Technology \\ (EPFL), CH-1015, Lausanne, Switzerland. \\ ${ }^{5}$ Grupo de Investigación en Remediación Ambiental y Biocatálisis, Instituto de Química, Facultad de \\ Ciencias Exactas y Naturales, Universidad de Antioquía, A.A. 1226, Medellín, Colombia. \\ *E-mail: ricardo.torres@udea.edu.co
}

doi: $10.20964 / 2016.09 .23$

Received: 2 April 2016 / Accepted: 26 June 2016 / Published: 7 August 2016

Solutions of the organic pollutant model, Crystal Violet (CV), were subjected to ultrasonic, electrochemical treatment and its combination. Ultrasound was tested at two frequencies $(20 \mathrm{kHz}$ or $800 \mathrm{kHz}$ ) and $80 \mathrm{~W}$ in deionized water. After $120 \mathrm{~min}, 20 \mathrm{kHz}$ conducted to $6 \% \mathrm{CV}$ degradation, while $50 \%$ elimination was observed at $800 \mathrm{kHz}$. No mineralization of the organic matter was detected in either case. Electrochemistry, using sulfate $\left(0.35 \mathrm{~mol} \mathrm{~L}^{-1}\right)$ with $\mathrm{IrO}_{2}$ or Boron Doped Diamond (BDD) electrodes at $20 \mathrm{~mA} \mathrm{~cm}$, was also evaluated. After $45 \mathrm{~min}$ the $\mathrm{IrO}_{2}$ and the $\mathrm{BDD}$ electrodes conducted to $8 \%$ and $95 \%$ degradation of the initial substrate; while $15 \%$ and $43 \%$ mineralization, respectively, was removed after $120 \mathrm{~min}$. The impact of anions was as follows: $3 \mathrm{mM}$ bicarbonate enhanced $800 \mathrm{kHz}$ ultrasonic yields, presence of chloride and sulfate benefit electro-oxidation with $\mathrm{IrO}_{2}$ and $\mathrm{BDD}$ electrodes respectively. $\mathrm{CV}$ oxidation at an electrode surface can be synergistically improved by ultrasound action at $20 \mathrm{kHz}$ and $800 \mathrm{kHz}$. In the best combination tested (BDD electrode and $800 \mathrm{kHz}$ ultrasonic wave), $\mathrm{CV}$ was removed in $45 \mathrm{~min}$, while $80 \%$ of the initial organic carbon was eliminate using BDD electrode and $800 \mathrm{kHz}$ ultrasonic wave. 
Keywords: Sonolysis; Electrolysis; Sonoelectrolysis; Crystal violet dye

\section{FULL TEXT}

(C) 2016 The Authors. Published by ESG (www.electrochemsci.org). This article is an open access article distributed under the terms and conditions of the Creative Commons Attribution license (http://creativecommons.org/licenses/by/4.0/). 